\title{
Vulnerability Studies of E2E Voting Systems
}

Lauretha Rura, Swinburne University of Technology, Malaysia

\author{
Biju Issac \\ Teesside University, UK \\ Manas Haldar \\ Swinburne University of Technology, Malaysia
}

CISSE 2012

$7^{\text {th }}-9^{\text {th }}$ December 2012 


\section{Introduction}

- Key concerns of elections

- Trust

- Transparency
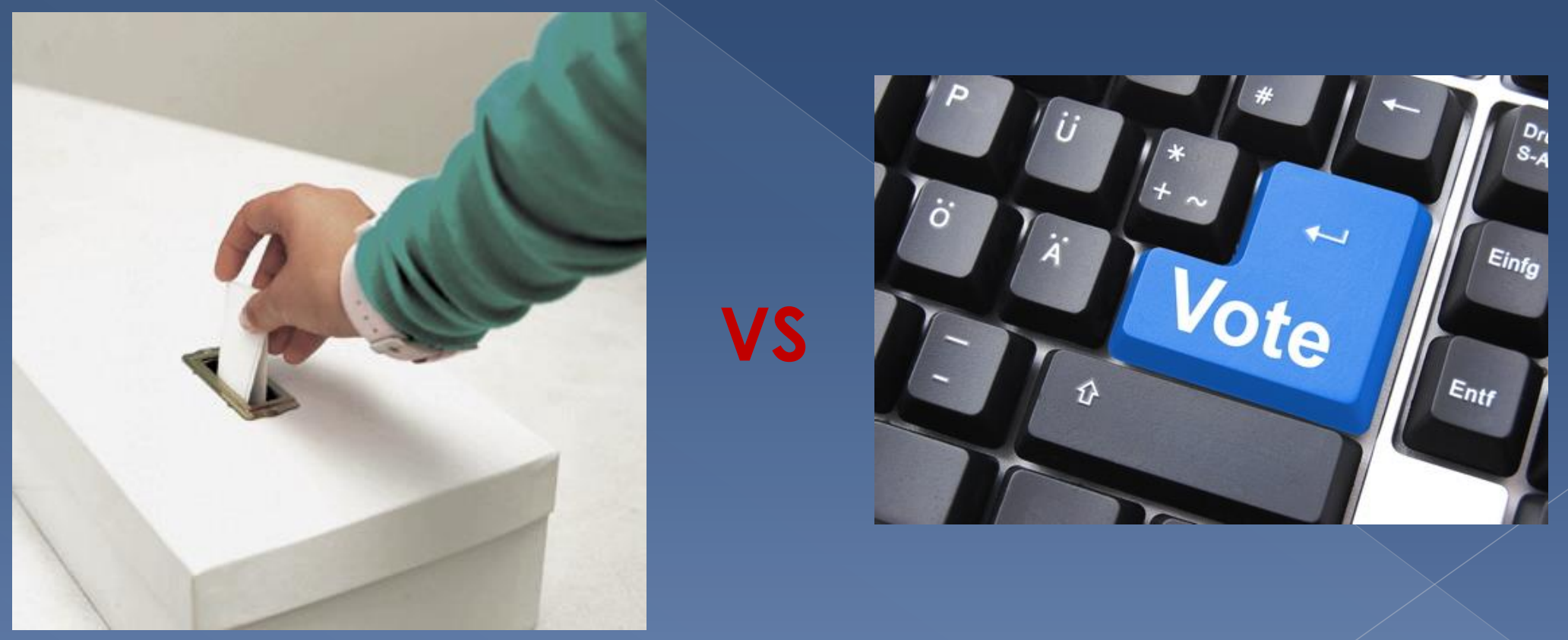

Paper-ballot Voting

E-Voting System 


\section{End-to-End Verifiable System}

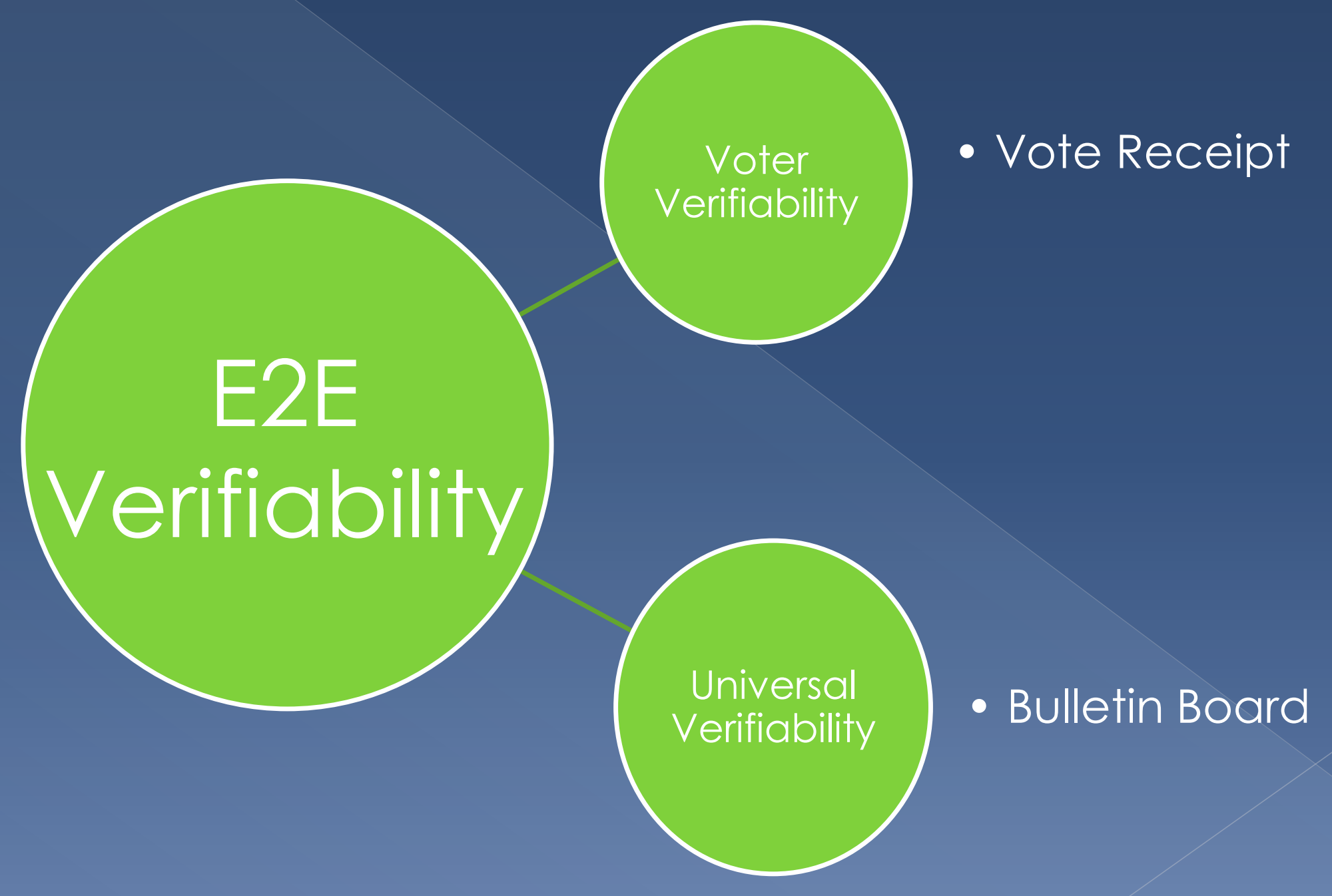




\section{Related E2E Voting Systems}

○ Helios

> Open-source web-based open-audit voting system that offers verifiable online elections for anyone (B. Adida, 2008).

$>$ Ensures ballot secrecy and election integrity (low coercion)

> Divided into two main categories:

- Ballot Preparation

- Ballot Casting

- Smart Ballot Tracker and Ballot Tracking Center (Bulletin Board) for vote verification 


\section{helios}

Data Privacy Day 2011 Company of the Year: Twitter - Voters and Ballot Tracking Center [back to election]

Who can vote?

- any facebook user

- any twitter user

- any google user

- any yahoo user

search search

\section{0 cast votes}

Voters 1 - 50 (of 165) next 50

\begin{tabular}{|c|c|}
\hline Name & Smart Ballot Tracker \\
\hline f Sophie Luu & 9scWvNiaWypRUK9JIXP2po6tCLVBNLi4vZoeDr85pFs [view] \\
\hline f Lauretha Rura & QaVoWh9PQ3Lv7rY3gSFWds8uIa7ASiwnfUYTJL1GV/C [view] \\
\hline E Alan_Wolf & RKC1GBJp26nZRF10zPmb/TSx6u5eWPK+/Y5Pvkh4zQS [view] \\
\hline Alberto de la Torre & zk0wpdShmFq90T1xWCTfXvryaBB4nqPXezAX1CYpLEU [view] \\
\hline Alex Cooper & ELuvWGGblBueAnCyq0/GsrN1CHgyjI+0psl8NgZwkXE [view] \\
\hline Andre Brioso & qgjhUaoxpl1TsbrLI1NF+TbgLpzWCOfDpDo58uyFRtk [view] \\
\hline $\mathbf{Y}$ ! Andreas Taousianis & goRROSnMJb3d70BPjoq902jipCH9REu8qN9CvGPKr5U [view] \\
\hline
\end{tabular}




\section{helios}

\section{Cast Vote QaVoWh9P}

cast in Data Privacy Day 2011 Company of the Year: Twitter

Fingerprint: QaVoWh9PQ3LV7rY3gSFWds8uIa7ASIWnfUYTJL1GV/c

by Lauretha Rura

details

\{"answers": [\{"choices": [ $\{$ "alpha":

"120047447885137451225144255856911682875386403759569861532352102728106172768145383286756673342249118 巨 6911282844821642512212014546512949069161977790700693837544211253094913808272201762515174382831789580 2419273744869133317363266009603777050913906142554569360467451953045358163094619857389400352799483395 8280265723565754936318843404602496921346378152652174845887796792437728810276862066742153344962416295 6365535429392550137717046372000859614050019325236260045780599379244664551973903123499495708306444929 0451688429541287951813299169492697888626211089307419669099350053547743569545869611125295458715429638 $891826797902944687 "$, "beta":

"4870188803080900214478302638642165133395404798252781691867112805027171022734419187030502986818865706465954300851937479723041392330183687739159618212815306080892609534816275668307160338885788141261825

\section{Fig. 2 Helios Smart Ballot Tracker}


- Scantegrity II

$>$ Practical enhancement for optical scan voting systems that achieves increased election integrity through a novel use of confirmation codes printed on ballots in invisible inks (Chaum et. all, 2008).

> Improved version of two optical scan voting systems:

- Punchscan

- Scantegrity

> Invisible Inks Technology 


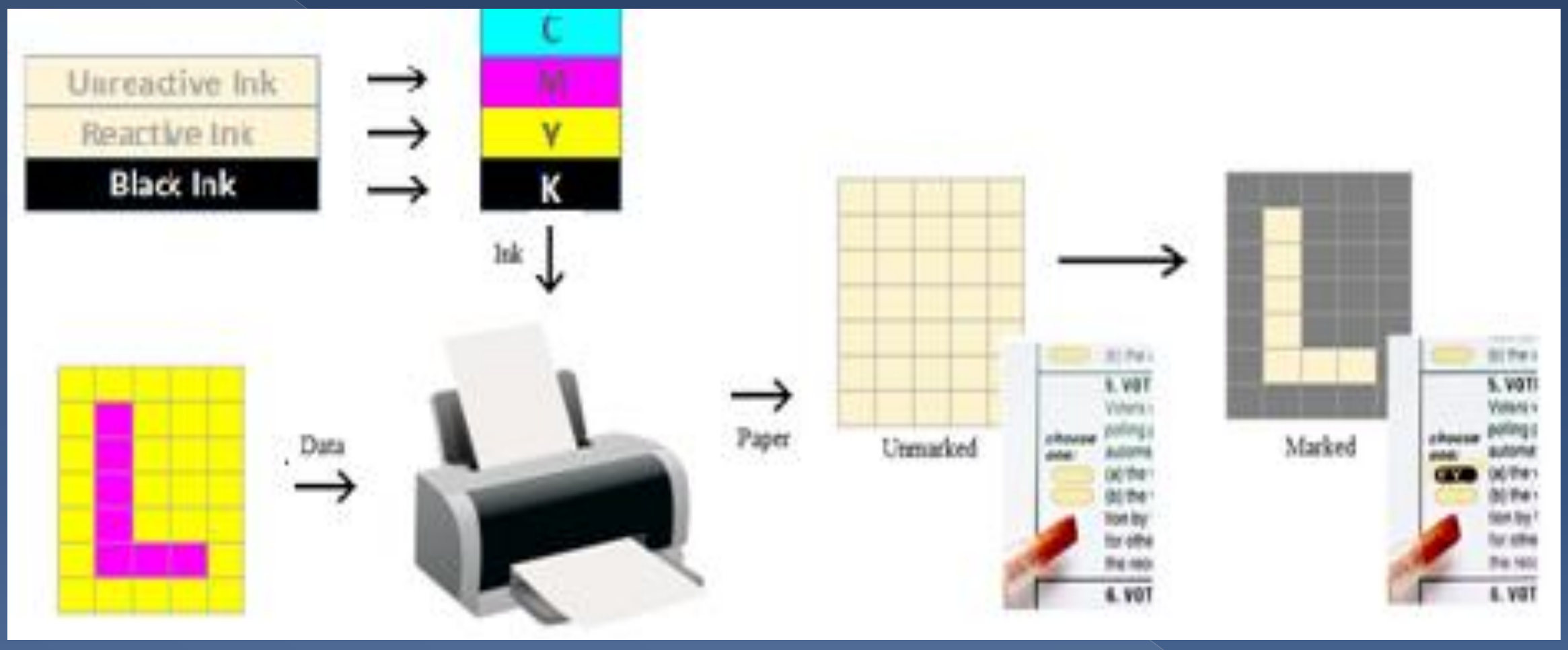

Fig. 3 Process of Invisible Ink Printing 
○ Prêt à Voter

> Paper-based ballot E2E voting system that ensures ballot secrecy and anonymity through the implementation of mix-net scheme.

> System's stages:

- Ballot Generation

- Vote Capture

- Vote Processing

- Auditing

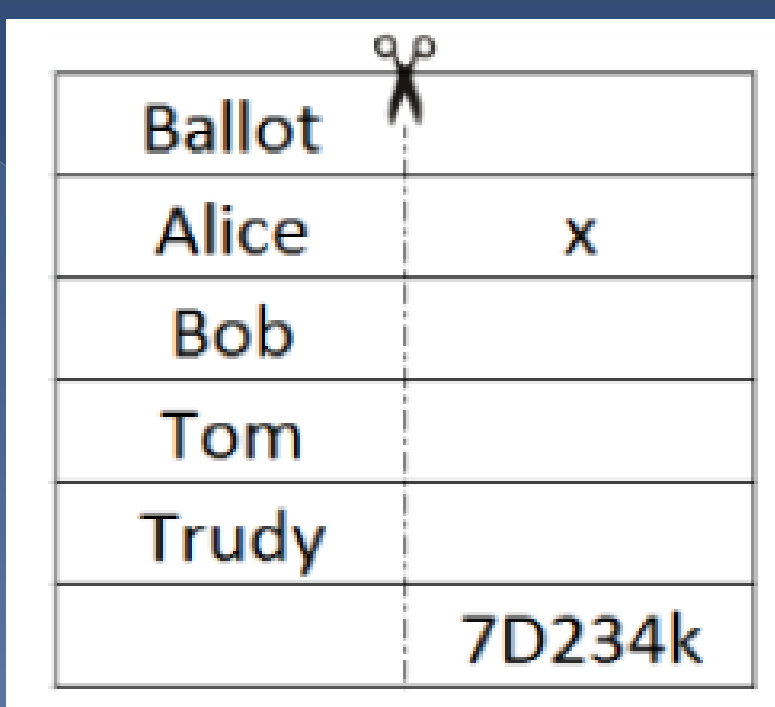

Fig. 4 Prêt à Voter's sample ballot 
o Rijnland Internet Election System (RIES)

> Combination of paper-based and non paperbased ballot voting systems with the assistance of its administrator called TTPI (Trusted Third Party Internetstemmen).

> Applied for the first time in 2004 Water Boards Election at Rijnland and De Dommel.

> Vote Casting:

- by Registered Mail

- Electronically

> System's stages:

- Initial Stage

- Election Stage

- Tally Stage 


\section{Proposed System: eVote}

- The implementation of cryptography and steganography in E2E voter verifiable remote electronic voting

- Cryptography is the art and science of keeping messages secure (B. Schneier, 1996), while Steganography is the art and science of hiding communication (Provos and Honeyman, 2003).

- Three Types of Users:

$>$ Administrators

$>$ Election Officers

$>$ Voters 


\section{System Design}

\section{Registration}

- Voter's registration process of eligible voters (identified by their respective organization's e-mail address).

\section{Authentication}

- Common login process with the implementation of password hashing to protect the voters' passwords.

Voting

- Encoded votes (visual cryptography) are distributed to the server and the voter as a receipt

Tallying

- Votes counting process by the officers (distributed keys is required to be presented all together)

Publishing and Vote Verification

- Voting result publication and verification through Bulletin Board 


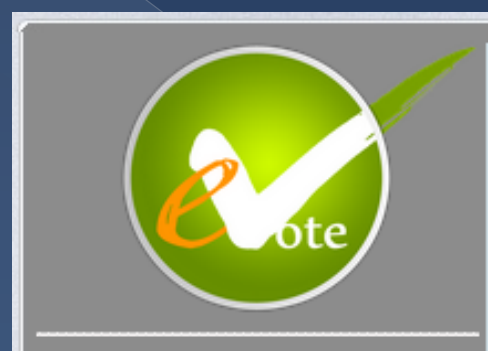

My Profile

Registered Voters

Tally

Logout

\section{Welcome to the E-Vote online voting system,} Hanni Stella!

As polling officer you are eligible to make some changes over voters' details following election.
Election Name:
Date Started:
Election
Date Ended:
11/11/12 10:49 PM
11/11/12 10:49 PM

Please take note that your activities are recorded in system administrators' archive

To retrieve tally, please insert your secret key. You can only access this feature once election ended and all the distributed secret keys are collected

\section{Fig. 5 Homepage of eVote voting system (officer's level)}



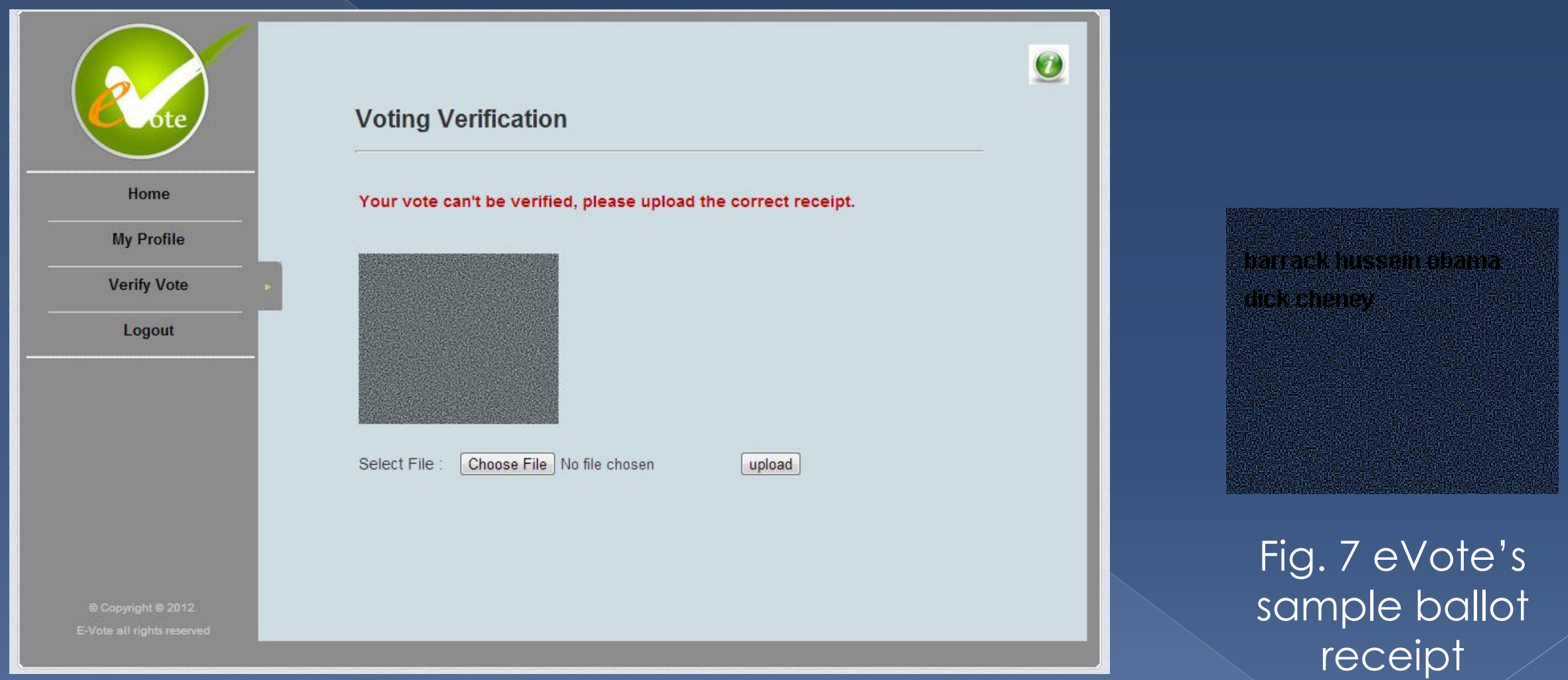

Fig. 6 eVote system voting verification feature.

Fig. 7 eVote's sample ballot receipt 


\section{E2E System Requirements and \\ Threats}

o Requirements:

$>$ Functional Requirements

$>$ Usability Requirements

$>$ Security Requirements

o Threats:

$>$ Internal Threats Sources

$>$ External Threats Sources

- Randomization Attack

- Simulation Attack

- Forced-abstention Attack

- DoS Attack 


\section{Comparison and Results}

> Comparison of E2E Voting Systems based-on E2E System Requirements

\begin{tabular}{|c|c|c|c|c|c|c|}
\hline \multicolumn{2}{|c|}{ Measurement } & \multirow{2}{*}{$\begin{array}{l}\frac{0}{\frac{0}{0}} \\
\frac{1}{1} \\
\text { High }\end{array}$} & \multirow{2}{*}{ 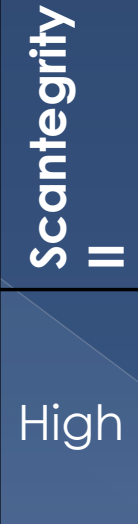 } & \multirow{2}{*}{$\begin{array}{l}\text { Med } \\
\text { Med }\end{array}$} & \multirow{2}{*}{ 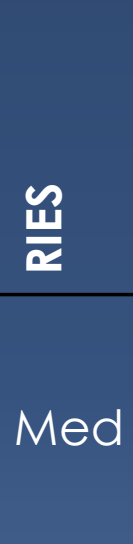 } & \multirow{2}{*}{$\begin{array}{l}\frac{0}{0} \\
\text { High }\end{array}$} \\
\hline \multirow{3}{*}{ 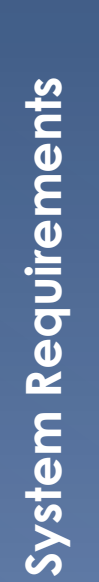 } & $\begin{array}{l}\text { Functionality } \\
\text { Requirements }\end{array}$ & & & & & \\
\hline & $\begin{array}{l}\text { Usability } \\
\text { Requirements }\end{array}$ & LoW & Med & Med & Med & Med \\
\hline & $\begin{array}{l}\text { Security } \\
\text { Requirements }\end{array}$ & High & Med & Low & Med & High \\
\hline
\end{tabular}




\section{Comparison and Results}

> Comparison of E2E Voting Systems based-on its Defense Mechanism against External Threats Sources

\begin{tabular}{|c|c|c|c|c|c|c|}
\hline \multicolumn{2}{|c|}{ Threats } & \multirow{2}{*}{$\frac{\frac{00}{9}}{\frac{0}{10}}$} & \multirow{2}{*}{ 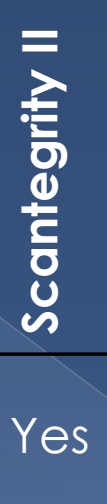 } & \multirow{2}{*}{$\frac{z}{\text { Yes }}$} & \multirow{2}{*}{$\frac{\frac{m}{\alpha \underline{\alpha}}}{\text { Yes }}$} & \multirow{2}{*}{$\frac{\frac{10}{0}}{\frac{N}{20}}$} \\
\hline \multirow{4}{*}{ 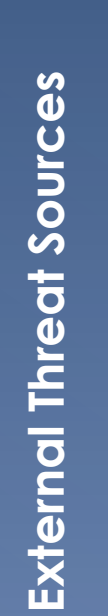 } & $\begin{array}{l}\text { Randomization } \\
\text { Attack }\end{array}$ & & & & & \\
\hline & $\begin{array}{l}\text { Simulation } \\
\text { Attack }\end{array}$ & Yes & No & Yes & No & Yes \\
\hline & $\begin{array}{l}\text { Forced- } \\
\text { absention } \\
\text { Attack }\end{array}$ & Yes & Yes & Yes & Yes & No \\
\hline & DoS Attack & Yes & Yes & Yes & Yes & Yes \\
\hline
\end{tabular}




\section{Conclusion}

> We believe the implementation of cryptography and steganography schemes in eVote system are sufficient to provide a secure, reliable and convenient voting system for medium range election.

> However, based on our comparison we found out that E2E voting systems are not fully resistant over attacks from the adversary. They can only fulfil a certain level of security.

$>$ Ergo, flexible system would be the best option at this moment. The users could adjust the system easily according to their skills and requirements. 
$Q$ \& $A$ 